\title{
COMPORTAMENTO DE LARVAS INFESTANTES DE Boophilus microplus EM PASTAGEM DE Brachiaria decumbens ${ }^{1}$
}

\author{
BEHAVIOUR OF Boophilus microplus LARVAE IN Brachiaria decumbens PASTURE
}

\author{
Ceres Lourenço Barreto Gauss ${ }^{2}$ John Furlong ${ }^{3}$
}

RESUMO

\begin{abstract}
O comportamento de larvas de Boophilus microplus em pastagem de Brachiaria decumbens com diferentes dias de descanso para pastoreio bovino foi observado em experimento conduzido na Embrapa Gado de Leite, Coronel Pacheco, MG, Brasil. Foram utilizados grupos com cinco bezerras 7/8 Holandês $x$ Zebu, os quais foram expostos em áreas de $100 \times 20 \mathrm{~m}$, submetidas a descanso de pastoreio por 0,15,30,45 e 60 dias, durante 72 horas. Após esse período, os bovinos foram estabulados em baias coletivas e, a partir do $15^{\circ}$ dia, mantidos em baias individuais com piso ripado, apropriado para a coleta de carrapatos adultos. Os resultados indicaram que são necessários, pelo menos, 60 dias de descanso para reduzir a população de larvas infestantes e permitir que essa prática seja utilizada como medida complementar para o controle do carrapato. Os dados obtidos foram submetidos à análise de regressão polinomial. Estimou-se em 82,6 dias o período necessário para uma completa limpeza da pastagem.
\end{abstract}

Palavras-chave: Boophilus microplus, larva, comportamento, Brachiaria decumbens.

\section{SUMMARY}

The behaviour of Boophilus microplus larvae in pasture of Brachiaria decumbens with different days of resting for cattle feeding was observed at Embrapa Dairy Cattle, Coronel Pacheco, MG, Brazil. Groups with five calves 7/8 Holstein x Zebu which were exposed to paddocks with $100 \times 20 \mathrm{~m}$ and resting feeding period of $0,15,30,45$ and 60 days during 72 hours. After this time, calves were removed and housing. After the fifteenth day they were kept in individual boxes appropriate for tick collection. Results indicated that at least 60 days of paddock resting are necessary for reduction in the infesting larvae population and recommend this handling practice to be used as a complementary measure for tick control. Data were submitted to polynomial regression. A period of 82.6 days was estimated for a complete cleaning of the pasture.

Key words: Boophilus microplus, larvae, behaviour, Brachiaria decumbens.

\section{INTRODUÇÃO}

O Boophilus microplus (Canestrini, 1887) é um ectoparasito que está distribuído por todo o mundo entre os Paralelos $30^{\circ} \mathrm{S}$ e $40^{\circ} \mathrm{N}$, exceto nos Estados Unidos da América, onde foi erradicado, e nas áreas muito altas ou muito áridas (CORDOVÉS, 1996). Devido à utilização em larga escala, de pastagem composta por Brachiaria decumbens, na região Sudeste do Brasil, torna-se de grande importância o estudo do comportamento infestante das larvas de Boophilus microplus nesta pastagem.

Com a finalidade de controlar a população de carrapatos e conseqüentemente os prejuízos causados por estes, é importante o estudo do seu ecossistema e dos fatores que interferem na sua sobrevivência, tais como condições climáticas, manejo do rebanho, manejo do pasto e tipo de

\footnotetext{
${ }^{1}$ Parte da dissertação de mestrado apresentada pelo primeiro autor à Universidade Federal de Juiz de Fora, Juiz de Fora, MG.

${ }^{2}$ Médico Veterinário, Mestre.

${ }^{3}$ Médico Veterinário, Doutor, Pesquisador da Embrapa Gado de Leite, Rua Eugênio do Nascimento, 610, 36038-330, Juiz de Fora, MG.

E-mail:john@cnpgl.embrapa.br. Autor para correspondência.
} 
vegetação. O mau manejo, associado ao uso indevido e exacerbado de acaricidas, ocasiona resistência dos carrapatos às drogas disponíveis, contribuindo, assim, para o agravamento do problema. Com este trabalho, espera-se contribuir para o esclarecimento mais preciso de técnicos e produtores rurais, no sentido de quantificar os benefícios do descanso de pastagem para o controle eficaz do carrapato.

O conhecimento a respeito da disponibilidade e longevidade das larvas no ambiente tem sido utilizado como, além de um componente do ciclo biológico, um indicativo para o tempo mínimo necessário para o descanso da pastagem, capaz de exercer um efeito limitante ao desenvolvimento das populações, com base em modelos de simulação (HARLEY \& WILKINSON, 1971; DE LA VEGA, 1981; HAZARI \& MISRA, 1993).

O objetivo deste estudo é aprofundar, através de metodologia mais aprimorada, o trabalho de FURLONG (1998) no ecossistema formado por Brachiaria decumbens, onde a análise estatística mostrou um padrão de comportamento das larvas não condizente com os resultados observados a campo.

\section{MATERIAL E MÉTODOS}

O experimento foi realizado no Campo Experimental de Coronel Pacheco da Embrapa Gado de Leite, no município de Coronel Pacheco, Zona da Mata do Estado de Minas Gerais, Brasil, W Gr40 15', S 21 $1^{0} 35^{\prime}$, Hp 435m, clima, segundo a classificação de Koeppen "Cwb", tropical de altitude, com semestre de inverno seco e verões brandos. A precipitação pluvial anual média é $1.581 \mathrm{~mm}^{3}$, a temperatura média é $21^{\circ} \mathrm{C}$ e a umidade relativa do ar é 78.8\% (MAARA, 1992 ).

Esta pesquisa foi desenvolvida em $\boldsymbol{B}$. decumbens, no período de 17 de janeiro a 07 de abril no ano 2000. Foi utilizada uma área de aproximadamente 1ha, naturalmente pastejada por bovinos infestados com B. microplus, desde três meses antes do início do experimento. Um dia antes do início do experimento, considerado dia -1 , a área foi vedada aos animais e demarcada em cinco parcelas de aproximadamente $100 \times 20 \mathrm{~m}$.

As parcelas foram pastejadas alternadamente aos $0,15,30,45$ e 60 dias de vedação da pastagem, por um período de 72 horas, por três grupos de cinco bezerras 7/8 Holandês x Zebu, com aproximadamente 160 quilos, seis meses de idade e com experiência prévia com carrapatos. O horário de entrada e saída dos animais da parcela foi estabelecido em 09:30h. As observações do comportamento dos animais foram feitas diariamente das 09:30h até às 16:30h. Após os três dias de pastejo, os animais foram mantidos em baias coletivas, isentas de carrapatos. No $15^{\circ}$ dia de estabulação os animais foram contidos em baias individuais, com piso ripado, também isentas de carrapatos, com água e alimento disponível, aí permanecendo até a queda de todas as fêmeas ingurgitadas, as quais foram recuperadas e contadas diariamente. Uma vez pastejada a parcela, esta não foi mais utilizada nos períodos seguintes.

Os números das contagens de fêmeas ingurgitadas recuperadas dos animais foram transformados para a escala logarítmica e analisados por regressão polinomial, incluindo-se a idade das larvas como variável independente, obtendo-se uma equação para descrever o comportamento da variável (BOX \& DRAPER, 1987).

Os dados climatológicos (temperatura, umidade relativa do ar e precipitação pluviométrica) foram obtidos na estação meteorológica do campo experimental de Coronel Pacheco, no município de Coronel Pacheco, Minas Gerais, Brasil.

\section{RESULTADOS}

Apresentam-se na figura 1 , as médias mensais de temperatura, precipitação pluviométrica e umidade relativa do ar durante o período de outubro de 1999 a maio de 2000. A análise estatística por regressão polinomial, do logaritmo do número de fêmeas ingurgitadas $\left(\mathrm{x}^{2}\right)$ recuperadas dos grupos de animais, apresentou a equação $\mathrm{Y}=3,2797+0,0365276 \mathrm{X}-0,00092276 \mathrm{X}^{2}$, com $\mathrm{R}^{2}=80 \%$, onde se percebe a redução da disponibilidade de larvas infestantes de $\mathbf{B}$. microplus com 60 dias de idade, na pastagem e a estimativa de que seriam necessários 82,6 dias de vedação para a ocorrência da mortalidade de todas as larvas infestantes. Pode-se observar a superposição dos valores obtidos e dos estimados, em decorrência do elevado coeficiente de regressão encontrado $\left(\mathrm{R}^{2}=80 \%\right)$, expresso na figura 2 .

\section{DISCUSSÃO}

A análise de regressão, observada na figura 2, indica uma relação inversa entre a idade das larvas no pasto e o número de larvas sobreviventes, pois à medida que o tempo $\mathrm{t}$ aumentava, o número de fêmeas ingurgitadas recuperadas ia progressivamente diminuindo até alcançar um valor nulo. Baseando-se no trabalho realizado por FURLONG (1998), para o atual estudo 


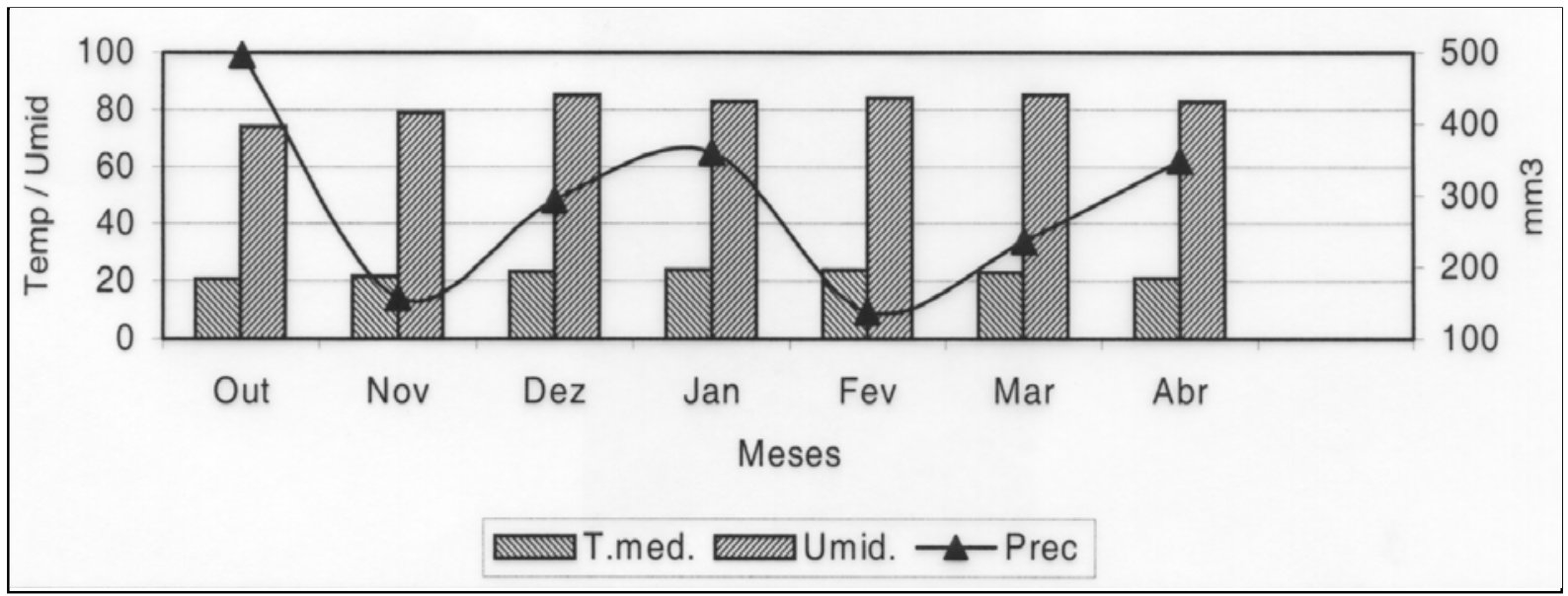

Figura 1 - Médias mensais de temperatura média (T. med.) $\left({ }^{\circ} \mathrm{C}\right)$, umidade (Umid.) (\%) e precipitação pluviométrica (Prec.) (mm $\left.{ }^{3}\right)$, no Campo Experimental de Coronel Pacheco-Embrapa Gado de Leite, Coronel Pacheco, MG, Brasil, durante o período de outubro de 1999 a abril de 2000.

foi verificado que houve um decréscimo progressivo do número total de fêmeas ingurgitadas recuperadas. Observou-se uma diminuição a partir dos 45 dias de idade das larvas, alcançando níveis mais baixos aos 60 dias, em conformidade com os resultados obtidos por GONZALES (1993). De acordo com os valores apresentados na figura 2, seriam necessários 82,6 dias para que o número de larvas na pastagem fosse reduzido a zero.

Utilizando-se como parâmetro a temperatura e o tempo de exposição das larvas no ambiente, verificou-se que a diminuição da quantidade de larvas na pastagem aos 45 dias sugere que a ausência de hospedeiro e o calor atuaram provavelmente acelerando a morte das mesmas por inanição, de acordo com as observações feitas por GONZALES et al. (1975). Para HITCHCOCK (1955), as larvas são mais vulneráveis do que os ovos às baixas temperaturas, e o seu tempo de sobrevivência é influenciado pelas condições de temperatura e umidade relativa às quais o embrião foi submetido. Como as reservas de alimento armazenadas pela larva são provenientes do núcleo embrionário e seus derivados, sua sobrevivência também estará comprometida (BALASHOV, 1968). Aos 60 dias de idade larval, verificou-se uma diminuição da temperatura média mensal para $21,1^{\circ} \mathrm{C}$, tendo a temperatura mínima alcançado $16^{\circ} \mathrm{C}$,

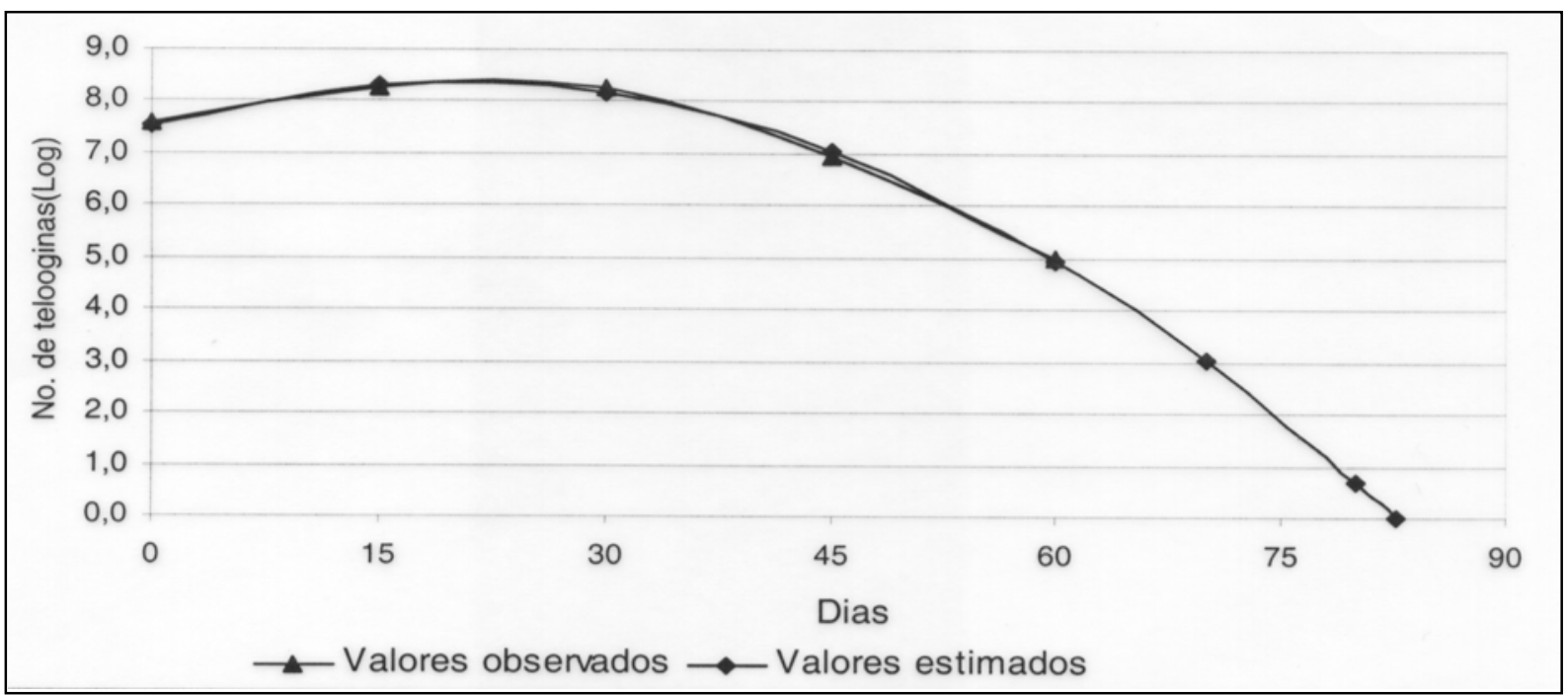

Figura 2 - Valores observados (transformados em logaritmo) e estimados por análise de regressão polinomial, do número de fêmeas ingurgitadas de Boophilus microplus recuperadas de Brachiaria decumbens, em função dos dias de vedação da pastagem, no Campo Experimental de Coronel Pacheco- Embrapa gado de Leite, Coronel Pacheco, MG, Brasil, no período de 17 de janeiro a 7 de abril de 2000. 
sugerindo que a menor quantidade de larvas no pasto pode ser explicada tanto pela menor viabilidade dos ovos que fizeram eclodir larvas mais fracas quanto pelo desgaste energético, dessecação e morte, sofrido durante a migração vertical em busca de melhores condições do microclima e retorno à posição de espera, na extremidade do capim, que ocorre naturalmente quando a larva não consegue achar um hospedeiro (SONENSHINE, 1993; THOMPSON et al., 1978; CORDOVÉS, 1996; SOUZA, 1999; NASCIMENTO, 2000).

Aos 60 dias de idade larval, a umidade relativa do ar mensal média foi mantida em nível superior a $80 \%$. Possivelmente a precipitação pluviométrica contribuiu para a diminuição da densidade de larvas, pois neste período a média mensal foi $349 \mathrm{~mm}^{3}$, superior aos meses de fevereiro e março. Observações semelhantes obteve RAWLINS (1979), o qual verificou que precipitação pluviométrica acima de $150 \mathrm{~mm}^{3} /$ mês causa danos físicos e gasto energético nas larvas na pastagem pelos deslocamentos em busca de locais privilegiados para o encontro com o hospedeiro. Para HITCHCOCK (1955), as larvas são dependentes da umidade relativa, porém atmosferas saturadas em relação à umidade relativa não são favoráveis à sua sobrevivência, pois as tornam letárgicas, sobrevivendo por períodos mais curtos do que se estivessem em umidades relativas mais baixas.

A diminuição da quantidade de larvas no pasto a partir de 45 dias sugere morte por esgotamento energético, em função do tempo de descanso da pastagem. Quanto ao tempo de descanso necessário para uma redução significativa da infestação do pasto, foi verificado que os dados apresentados por FURLONG (1998) demonstraram um tempo necessário para redução de infestação, para 10 ou menos larvas, superior a 75 dias, para vedações que iniciaram em janeiro e fevereiro. Provavelmente as diferenças observadas foram devidas à metodologia empregada pelo autor, pois foram utilizados apenas dois animais traçadores, obtendo um coeficiente de regressão de 40 a $50 \%$, acrescido do menor tempo de permanência dos mesmos na parcela, 16 horas. Possivelmente a redução de tempo de pastejo e densidade de hospedeiro muito baixa em contato com as larvas na parcela, tenham contribuído para que menos larvas se fixassem a eles.

Foram observados dois picos de infestação, sendo um em fevereiro e outro em março, nas vedações de 15 e 30 dias, respectivamente. Estas observações estão de acordo com as de SOUZA et al. (1986), que verificaram que as menores infestações por carrapatos ocorreram de agosto a novembro e as maiores de janeiro a abril, sugerindo que estas larvas foram provenientes de fêmeas ingurgitadas expostas nos meses de setembro, outubro, novembro e dezembro, com encurtamento do período de pré-postura até a eclosão das larvas, determinando um acúmulo de larvas em janeiro e fevereiro. Também estão de acordo com SERRA-FREIRE et al. (1990), que reconheceram dois picos distintos de B. microplus na pastagem, um entre setembro e dezembro e outro entre fevereiro e abril, na região da Baixada Fluminense, no Município do Rio de Janeiro.

$\mathrm{O}$ aumento do número de larvas nas parcelas de 15 e 30 dias, no mês de fevereiro e março, provavelmente ocorreu devido às ótimas condições de temperatura, onde a média mensal foi de $24^{\circ} \mathrm{C}$ que, aliada à umidade relativa do ar superior a $80 \%$, contribuiu para um aumento da sobrevivência. De acordo com UTECH et al. (1983), temperaturas até $25^{\circ} \mathrm{C}$ não interferem na sobrevivência larval de B. microplus, sendo até favorável se associadas a umidades relativas altas, pois assim estas não perdem água para o meio. Em adição ao exposto, VERÍSSIMO \& MACHADO (1995) afirmaram que umidade com valores abaixo de $80 \%$ contribui negativamente para o desenvolvimento embrionário e sobrevivência larval na pastagem.

Possivelmente relacionado ao aumento da sobrevivência larval foi a condição ideal do microclima oferecido pela B. decumbens, pois segundo SAUERESSIG (1994), este é o capim mais favorável à sobrevivência larval se comparado ao Andropogon gayanus e à pastagem nativa dos cerrados do Distrito Federal. No microclima a vegetação atua como uma proteção contra as condições adversas do macroambiente ( SONENSHINE, 1993b).

Durante a permanência dos animais na parcela, foi observado que o rebanho se deslocava seguindo um animal guia, ou seja, aquele que se destacava, indo sempre à frente dos demais (CORDOVÉS, 1996; ARNOLD, 1985). Foi verificado que os animais guia, B, G, P, B, (Tabela 1), foram respectivamente, os das parcelas $0,15,30$ e 45 dias, apresentando uma maior infestação em comparação com o restante do grupo, e que o animal guia da parcela 60 dias foi o animal $\mathrm{F}$, quando o esperado seria o animal $\mathrm{G}$, já que o grupo desta parcela foi uma repetição daquele que pastejou na parcela de 15 dias. Assim sendo, pode-se inferir uma mudança de posição hierárquica dentro do grupo, provavelmente em decorrência de fatores genéticos, já que todos os animais eram fêmeas e o grupo era 
Tabela 1 - Número de fêmeas ingurgitadas de Boophilus microplus recuperadas dos animais que pastejaram nas parcelas com $0,15,30,45$ e 60 dias de vedação, no Campo Experimental de Coronel Pacheco - Embrapa Gado de Leite, Coronel Pacheco, MG, no período de 17 de janeiro a 7 de abril de $2000^{*}$.

\begin{tabular}{ccccc}
\hline DIA 0 & DIA 15 & DIA 30 & DIA 45 & DIA 60 \\
\hline $844(\mathrm{~A})$ & $900(\mathrm{~F})$ & $2397(\mathrm{~L})$ & $831(\mathrm{~A})$ & $357(\mathrm{~F})+$ \\
$1517(\mathrm{~B})+$ & $3688(\mathrm{G})+$ & $2939(\mathrm{M})$ & $955(\mathrm{~B})+$ & $80(\mathrm{G})$ \\
$774(\mathrm{C})$ & $1658(\mathrm{H})$ & $2041(\mathrm{~N})$ & $181(\mathrm{C})$ & $34(\mathrm{H})$ \\
$578(\mathrm{D})$ & $2168(\mathrm{I})$ & $631(\mathrm{O})$ & $459(\mathrm{D})$ & $72(\mathrm{I})$ \\
$1411(\mathrm{E})$ & $2576(\mathrm{~J})$ & $3159(\mathrm{P})+$ & $551(\mathrm{E})$ & $29(\mathrm{~J})$ \\
5124 & 10990 & 11167 & 2977 & 572 \\
\hline
\end{tabular}

*As letras entre parênteses indicam os animais nos quais foram recolhidas as fêmeas ingurgitadas.

+ indica os animais mais infestados.

formado pelos mesmos indivíduos, com mesma época de parição, peso e porte semelhantes, com experiência prévia com carrapatos e o ambiente não era desconhecido. Não foi observado nenhum tipo de interação agonística (brigas, marradas) entre elas que pudesse justificar a mudança de posição hierárquica dentro do grupo. Possivelmente os dados obtidos são em decorrência dos animais-guia entrarem em contato com a carga de larvas infestantes antes dos demais, como foi observado por CORDOVÉS (1996). Entretanto, maiores investigações na área de comportamento social de bovinos devem ser feitas para que resultados mais consistentes possam ser apresentados.

\section{CONCLUSÕES}

Em média, foram necessários 60 dias de vedação da pastagem de $\boldsymbol{B}$. decumbens no verão para que a quantidade de larvas infestantes de $\boldsymbol{B}$. microplus na pastagem fosse reduzida a níveis baixos. Estimou-se serem necessários 82,6 dias de exposição ao ambiente do experimento para que todas as larvas infestantes morressem. Uma maior quantidade de fêmeas ingurgitadas foi recuperada dos animais-guia. Observou-se também um pico de infestação na parcela de 15 dias e outro na de 30 dias de vedação.

\section{REFERÊNCIAS BIBLIOGRÁFICAS}

ARNOLD, G.W. Associations and social behaviour. In: FRASER, A.F. World animal science, - a basic information - ethology of farm animals. Rome : St. John's, 1985. Cap.20. p.233-246.

BALASHOV, Y.S. A translation of bloodsucking ticks (IXODOIDEA)- vectors of diseases of man and animals (By Olga G. Strekalovsky; Edited by H. Hoogstraal and R.J. Tatchell). Miscellaneous Publications of the Entomological Society of America, Hyattsville, v.8, n.5, p.1-376, 1968.
BOX, G.E.P., DRAPER, N.R. Empirical model-building and response surfaces. Willey series in probability and mathematical statistics. New York : John Willey \& Sons, 1987. 669p.

CORDOVÉS, C.O. Carrapato: controle ou erradicação. Alegrete : Gralha, 1996. 130p.

DE LA VEGA, R. New method for determination of viability of Boophilus microplus (IXODOIDEA, IXODIDAE) larvae. Folia Parasitologica, Prague, v.28, n.4, p.371-375, 1981.

FURLONG, J. Poder infestante de larvas de Boophilus microplus (ACARI:IXODIDAE) em pastagem de Brachiaria decumbens. Ciência Rural, Santa Maria, v.28, n.4 , p.635640, 1998.

GONZALES, J.C., SILVA, N.R. da, FRANCO, N.E., $\boldsymbol{e} \boldsymbol{t}$ al. A vida livre do Boophilus microplus (CAN., 1887). Arquivos da Faculdade de Veterinária da UFRGS, Porto Alegre, v.3, n. 1, p. $21-28,1975$.

GONZALES, J.C. O controle do carrapato do boi. Porto Alegre : Mestre Jou, 1993. 80p.

HARLEY, K.L.S., WILKINSON, M.A. A modification of pasture spelling to reduce acaricide treatments for cattle tick control. Australian Veterinary Journal, Collingwood, v.47, p.108-111, 1971.

HAZARI, M.M., MISRA, S.C. Behaviour and survival of Boophilus microplus larvae under outdoor conditions. Indian Veterinary Journal, Madras, v.3, n.2, p.187-88, 1993.

HITCHCOCK, L.F. Studies of the non-parasitic stages on the cattle tick, Boophilus microplus (CANESTRINI) (ACARINA:IXODIDAE). Australian Journal of Zoology, Collingwood, v.3, n.3, p.295-311, 1955.

MAARA. Secretaria Nacional. Normais climatológicas (19611990). Brasília, 1992. 84p.

NASCIMENTO, C.B. Comportamento, ecologia e biologia da fase de vida livre de Boophilus microplus (Canestrini, 1887) (Acari: Ixodidae) em pastagem de Pennisetum purpureum (Schum). Juiz de Fora, 2000. 40p. Dissertação (Mestrado em Biologia) - Curso de Pós-graduação em Ecologia e Comportamento Animal, Universidade Federal de Juiz de Fora, 2000.

RAWLINS, S.C. Seasonal variation in the population density of larvae of Boophilus microplus (Canestrini) (Acari: Ixodoidea) in Jamaican pastures. Bulletin of Entomological Research, Wallingford, v.69, p.87-91, 1979.

SAUERESSIG, T.M. Estudo da fase não parasitária do carrapato de bovinos em pastagens cultivadas e nativa no Distrito Federal. Planaltina : Embrapa Cerrados. 1994. 15p. (Boletim de Pesquisa, 37.)

SERRA-FREIRE, N.M., BONILHA, P.C., CAIAFA, R.M., et al. Avaliação da disponibilidade de estádios não-parasitários de ixodídeos em pastagem submetida ao pastejo contínuo por bovinos. Arquivos da Universidade Federal Rural do Rio de Janeiro, Rio de Janeiro, v.13, n.10, p.37-43, 1990.

SONENSHINE, D.E. Biology of ticks. New York : Oxford University, 1993. V.2. 
SOUZA, A.C. Comportamento e ecologia de larvas e fêmeas ingurgitadas do carrapato Boophilus microplus (CANESTRINI, 1887) (ACARI: IXODIDAE) em pastagem de Brachiaria decumbens. Juiz de Fora, 1999. 42p. Dissertação (Mestrado em Biologia) - Curso de Pósgraduação em Ecologia e Comportamento Animal, Universidade Federal de Juiz de Fora, 1999.

SOUZA, A.P. de, GONZALES, J.C., RAMOS, C.I., et al. Fase de vida livre e variação sazonal do carrapato no Planalto Catarinense. Florianópolis : EMPASC, 1986. 18p. (Comunicado Técnico, 102.)
THOMPSON, K.C.; ROA, J.E., ROMERO, T.N. Anti-grasses as the basis for developing practical tick control packages. Tropical Animal Health and Production, Edinburgh, v.10, p.179-182, 1978.

UTECH, K.B.W., SUTHERST, R.W., DALLWITZ, M. J., et al. A model of the survival of larvae of the cattle tick, Boophilus microplus, on pasture. Australian Journal of Agricultural Research, Collingwood, v.34, p.63-72, 1983.

VERÍSSIMO, J.C.; MACHADO, S.G. Fase de vida livre do ciclo evolutivo do carrapato Boophilus microplus. Zootecnia, Nova Odessa, v.33, n.2, p.41-53, 1995. 